\title{
Evaluation of membrane bioreactor for advanced treatment of industrial wastewater and reverse osmosis pretreatment
}

\author{
Majid Hosseinzadeh*, Gholamreza Nabi Bidhendi, Ali Torabian and Naser Mehrdadi
}

\begin{abstract}
The evaluation of a membrane bioreactor (MBR) for pretreatment of reverse osmosis (RO) in order to reuse and reclamation of industrial town wastewater treatment plant was investigated in this study. Performance of MBR effluent through water quality in term of parameters such as chemical oxygen demand (COD), total suspended solids (TSS), total nitrogen (TN) and total coliform (TC) were measured. Also Silt density index (SDI) was used as indicator for RO feed water. The results of this study demonstrated that MBR produce a high quality permeate water. Approximately 75\%,98\%, 74\% and 99.9\% removal of COD, TSS, TN and TC were recorded, respectively. Also $\mathrm{SDI}$ of the permeate effluent from membrane was below 3 for most of the times. It means that pilot yield a high quality treated effluent from the membrane module which can be used as RO feed water.
\end{abstract}

Keywords: Membrane bioreactor, Reverse osmosis, Silt density index, Fouling

\section{Introduction}

Nowadays water resources are becoming increasingly scarce in many areas of the world particularly in arid regions such as Middle East due to factors such as increasing population, climate changes, industrial development and increasing water use per capita, etc. Because of the scarcity of water resources, wastewater reclamation and reuse is an effective tool for sustainable industrial development program in both developing and developed countries. Currently, treated industrial wastewater is typically discharged to the environment in most industrial towns in Iran. These effluents have a potential to reclamation and reuse for produce industrial process water. For reach this reuse application further treatment would be needed. Nowadays membrane separation processes are becoming quite popular in wastewater treatment and reclamation, since they combine process stability with an excellent effluent quality [1-4]. One of this membrane processes for water reuse and reclamation is reverse osmosis (RO) that is increasingly being used in all over the world [5-9]. The main problem of using RO is its membrane fouling that is prevalent in water reclamation applications. In fact membrane fouling is the main cause of

* Correspondence: hosseinzadeh_m@ut.ac.ir

Graduate Faculty of Environment, University of Tehran, Tehran, Iran permeate flux decline and loss of product quality in reverse osmosis Systems $[10,11]$. Sources of fouling can be divided into four principal categories: scaling, particular fouling, bio fouling and organic fouling. To avoid common issues that can result in system failure, RO systems need to be coupled with an effective pretreatment.

MBR has been widely studied and applied on full scale in wastewater treatment and it is considered as a new pretreatment for reverse osmosis in water reclamation and reuse among many different pretreatment schemes for RO [12-18].

MBR is a process in which conventional biological system is coupled with the membrane process. There are two configurations for MBRs which are in-series and submerged MBRs which submerged membrane bioreactors have lower power requirements than the in-series configurations $[19,20]$.

Due to the shortage of water resources in the Shokouhieh industrial town (located in Qom province, Iran) reclamation and reuse of industrial wastewater treatment plant effluent using RO modules was put on the agenda. Effluents of this WWTP were not being adequately treated by biological treatment and there are biodegradable organic matters in effluent of wastewater treatment plant. This research has focused on the evaluation of the 
pilot scale operation and monitor of an MBR system to advance treatment of an industrial wastewater treatment plant effluent in order to produce water with appreciate quality as RO feed water. In other words this study has discussed the feasibility of RO pretreatment for water reuse from industrial wastewater treatment effluent (before disinfection) with operation of a MBR pilot. The removal of certain pollution parameters such as chemical oxygen demand (COD), suspended solids (SS), total nitrogen (TN) and total coliform (TC) were monitored.

\section{Material and methods}

\section{Effluent source}

Actual effluent used in this study as was taken from outlet of an industrial wastewater treatment plant of Shokouhieh, Qom, Iran. This plant receives and treats the wastewater from different factories such as welding, dairy, beverage, metal finishing, etc. Main units of Shokouhieh treatment plant are screens, an equalization tank, an anaerobic reactor, an aeration aerobic tank, sedimentation, sand filter and a disinfection system. Due to poor design, this existing treatment system is not effective in removing the all organic load of influent wastewater. Therefor there is significant amount of biodegradable organic matters in effluent. The effluent samples as MBR feed wastewater were collected from outlet of sand filters in plastic containers and were delivered to the laboratory where pilot is operated there. The typical physicochemical characteristics of the effluent are presented in Table 1. Values for parameters in Table 1 were measured from wastewater treatment plant effluent stream line after sand filters and before chlorination unit.

\section{MBR pilot unit}

Continuous operation of a pilot scale ultrafiltration membrane bioreactor system was carried out in this study. Schematic process flow diagram of pilot set up with a picture of system in operation is shown in Figure 1.

The bioreactor was made of Plexiglass with total volume of 32 liters. A flat sheet membrane ultrafilter was placed in the center of bioreactor. The membrane specifications are summarized in Table 2.

Membrane was operated at a constant flow rate of 4 L/hr using a prestaltic pump. Air blower was used to

\section{Table 1 Shokouhieh effluent characteristics}

\begin{tabular}{ccl}
\hline Parameter & Unit & Value \\
\hline $\mathrm{pH}$ & & $7.3 \pm 0.62$ \\
$\mathrm{SS}$ & $\mathrm{mg} / \mathrm{L}$ & $223 \pm 32$ \\
$\mathrm{COD}$ & $\mathrm{mg} / \mathrm{L}$ & $250 \pm 64$ \\
$\mathrm{~T}-\mathrm{N}$ & $\mathrm{mg} / \mathrm{L}$ & $51 \pm 30$ \\
$\mathrm{TC}$ & $\mathrm{MPN} / 100 \mathrm{~mL}$ & $1.75 \times 10^{6} \pm 35 \times 10^{4}$ \\
\hline
\end{tabular}

provide required sufficient air during operating the MBR. Air was introduced via perforated plastic tube air diffusers which were located at the bottom of the reactor to produce fine and coarse bubbles for supply dissolved oxygen required for biological process in the reactor and reduce fouling on the membrane, respectively. Also pilot was equipped with control instruments for measuring temperature, dissolved oxygen (DO), $\mathrm{pH}$ and wastewater level.

\section{Operating conditions}

MBR operating characteristics are summarized in Table 3. Membrane bioreactor was operated continuously, corresponding to an 8-hour hydraulic retention time (HRT) and the duration of operation was 30 days. Prior to use, membrane was washed with tap water until a steady pure water permeate flux was obtained. During operation, MLSS temperature in the bioreactor was kept constant at $22-27^{\circ} \mathrm{C}$ with a heat exchanger. Permeate flux was set to approximately $83 \mathrm{~L} / \mathrm{m}^{2} / \mathrm{hr}$ using a prestaltic pump and transmembrane pressure (TMP) was continuously recorded using an analogue pressure gage. Chemical cleaning of the membrane module was not carried out during the operation. No biomass was initially removed from the reactor to allow the biomass concentration build up in the system to about $2000 \mathrm{mg} / \mathrm{L}$. After that daily withdrawal of mixed liquor was conducted from the reactor in order to maintain the predetermined SRT (25 day) and control increase of organic matter and solid concentrations in the bioreactor.

The membrane was cleaned chemically once the pressure reached about $60 \mathrm{kPa}$. In this stage after taking out the membrane, it was soaked in a $250 \mathrm{mg} / \mathrm{L} \mathrm{NaOCl} \mathrm{so-}$ lution and afterwards with $4000 \mathrm{mg} / \mathrm{L}$ citric acid solution for at least 4 hours. Then membrane was cleaned with tap water. Fine bubble aeration was provided to maintain the dissolved oxygen (DO) concentration in the biological reactor higher than $2 \mathrm{mg} / \mathrm{L}$. Fine bubble aeration was accomplished using suitable diffusers placed at the bottom of the biological reactor. Also coarse bubble aeration was supplied to the membrane module to minimize membrane fouling.

\section{Analytical method}

Laboratory analyses were conducted to determine the characteristics of influent wastewater to pilot, activated sludge and MBR permeate. For this, suspended solids, chemical oxygen demand, total nitrogen and total coliform were analyzed. Most analytical techniques used in this research followed the standard methods described by APHA [21]. Data in this paper was averaged by at least 2 experiment results at each process. MLSS was measured with a Whatman glass microfiber filter using APHA 2540E standard method. The COD content of 


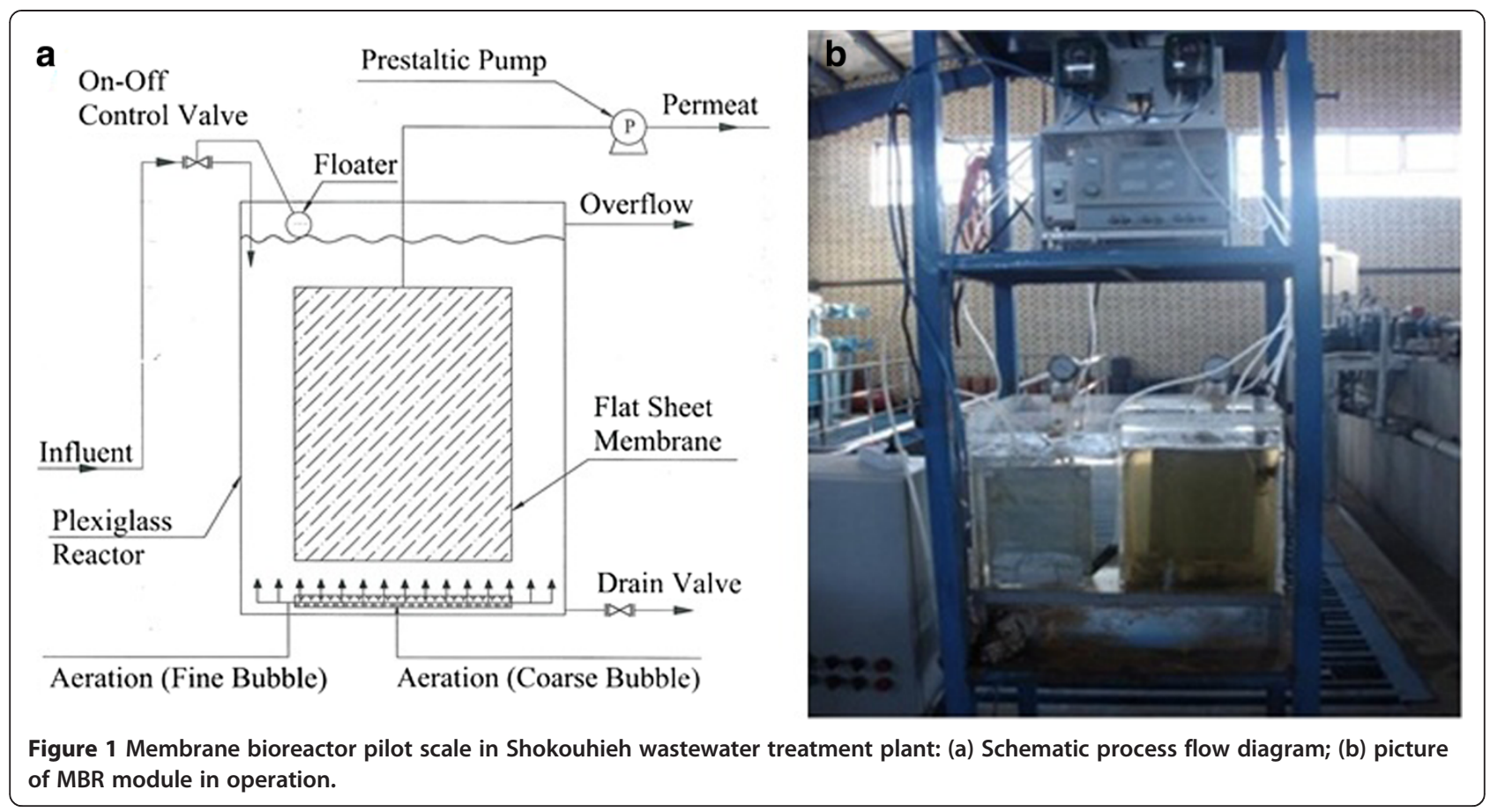

the samples was measured using Hach COD reactor and $\mathrm{TN}$ of the samples was measured using the Merck TN kit. The determination of total coliform was carried out for MBR feed and permeate samples using standard method 9222 B procedure.

The temperature of inlet and outlet stream of MBR and MLSS temperature in the reactor was monitored using a digital temperature probe (JENWAY, England ). These data were verified periodically using an alcohol thermometer. Also MBR influent and effluent $\mathrm{pH}$ value were determined using a portable $\mathrm{pH}$ meter (JENWAY370, England) and dissolved oxygen meter was used to determine DO level at reactor (JENWAY-970, England).

Field emission scanning electron microscopy (FESEM) technique for new membrane and used membrane was employed to investigate the morphology of membrane fouling due to the deposition of particle, biomass and other foulants. Also X-ray fluorescence (XRF) spectrometer was

Table 2 Specification of membrane

\begin{tabular}{lll}
\hline Process parameters & Unit & Value \\
\hline Membrane configuration & kDalton & Flat sheet \\
Cut off & $\mu \mathrm{m}$ & 150 \\
Pore size & $\mathrm{mm}$ & 0.4 \\
Dimensions (Width $\times$ Height) & $\mathrm{m}^{2}$ & $240 \times 200$ \\
Effective surface area & - & 0.048 \\
Material & - & EPS \\
Membrane charge & - & Neutral \\
pH resistance range & $4-11$ \\
\hline
\end{tabular}

used for chemical analysis of sediment layer. To do this used membrane sheets were taken off from MBR module. Tap water was sprayed at the surface to remove any particle and attached biomass. Then membrane was cut into small pieces by sterile blades under room temperature and sent to University of Tehran laboratory for XRF analysis and instant FESEM scanning.

Silt Density Index (SDI) analyses were performed on the MBR effluents to determine the fouling potential of MBR effluent as RO influent. This test is defined by its specific procedure (ASTM D-4189). SDI is based on the time required to filter a fixed volume of water through a standard $0.45 \mu \mathrm{m}$ pore size microfiltration membrane with a constant given pressure of $30 \mathrm{psi}$. The difference between the initial time and the time of a second

Table 3 Operation condition for MBR

\begin{tabular}{lcc}
\hline Process parameters & Unit & Value \\
\hline Mode of operation & ${ }^{\circ} \mathrm{C}$ & continuous \\
Operating temperature & $\mathrm{L} / \mathrm{hr}$ & $22-27$ \\
Permeate flow rate & $\mathrm{L} / \mathrm{m}^{2} / \mathrm{hr}$ & 4 \\
Filtration flux & - & 83 \\
pH in reactor & $\mathrm{hr}$ & $6.4-7.8$ \\
HRT & $\mathrm{day}$ & 8 \\
SRT & $\mathrm{mg} / \mathrm{L}$ & 25 \\
MLSS & $\mathrm{mg} / \mathrm{L}$ & $1700-2450$ \\
MLVSS & $\mathrm{mg} / \mathrm{L}$ & $1510-2230$ \\
Mixed liquor DO & & $2-4$ \\
\hline
\end{tabular}




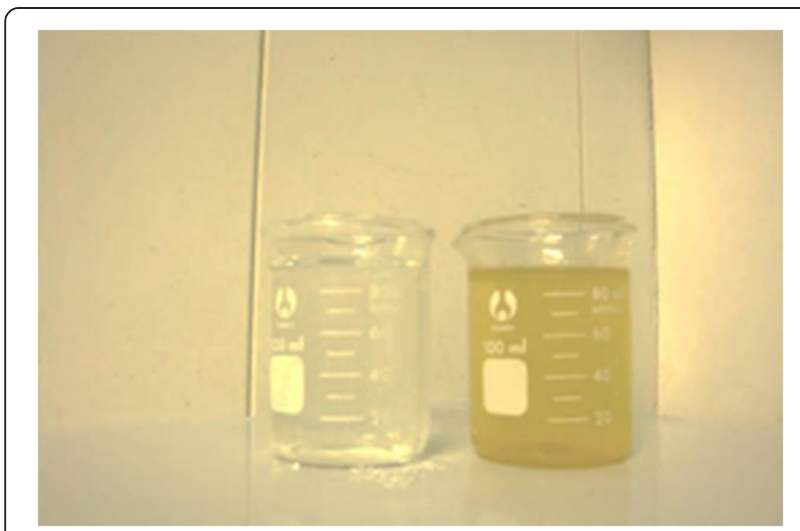

Figure 2 MBR mixed liquor and permeate water.

measurement after normally 15 minutes (after silt-built up) represents the SDI value and calculated as below:

$$
S D I=\frac{100 \times\left(1-\frac{t_{1}}{t_{2}}\right)}{T}
$$

In which:

$\mathrm{T} 1=$ the time required to filter the first $500 \mathrm{~mL}$

$\mathrm{T} 2=$ the time required to filter the second $500 \mathrm{~mL}$
$\mathrm{T}=$ the elapsed filtration time (normally 15 minutes) after the start of collecting the first $500 \mathrm{~mL}$

\section{Results and discussion}

\section{Permeate water quality of MBR}

Before start the experiments, at startup phase MBR module was operated for more than 5 weeks and the stable phase was obtained. At times, values of the MLSS concentration were measured and MLSS concentration was increased up to a value of around $2000 \mathrm{mg} / \mathrm{L}$ and after that sludge removal was initiated to maintain MLSS concentration constant in the reactor. During 30 days of operation of the reactor, MBR performance base on influent and effluent quality and removal percentage data of SS, COD, TN and TC showed that system has produced permeate water with excellent quality, as was shown in Figure 2.

Figure 3(a) shows the concentration of SS for inlet and outlet of MBR system and biosolids concentration (MLSS) versus the days of operation. Inlet SS concentration ranged from 179 to $243 \mathrm{mg} / \mathrm{L}$. During this study, it was detected that MLSS of pilot was in the range of $1700-2450 \mathrm{mg} / \mathrm{L}$. Because of the extend order of magnitudes of the concentration values, the

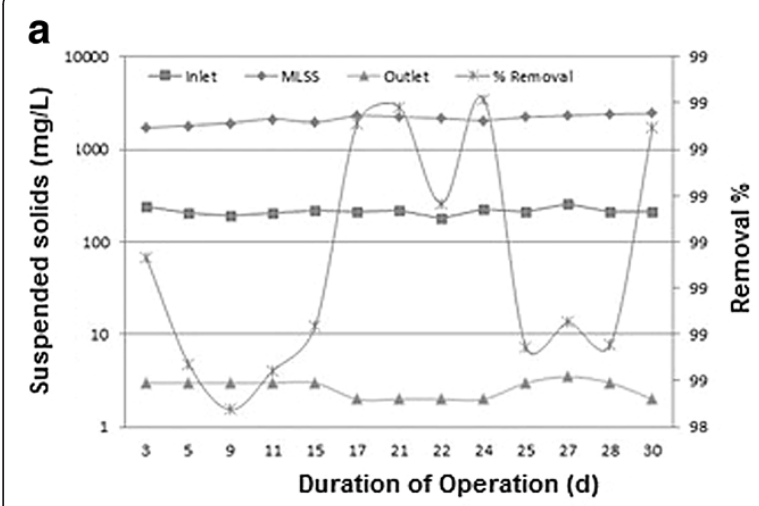

\section{b}
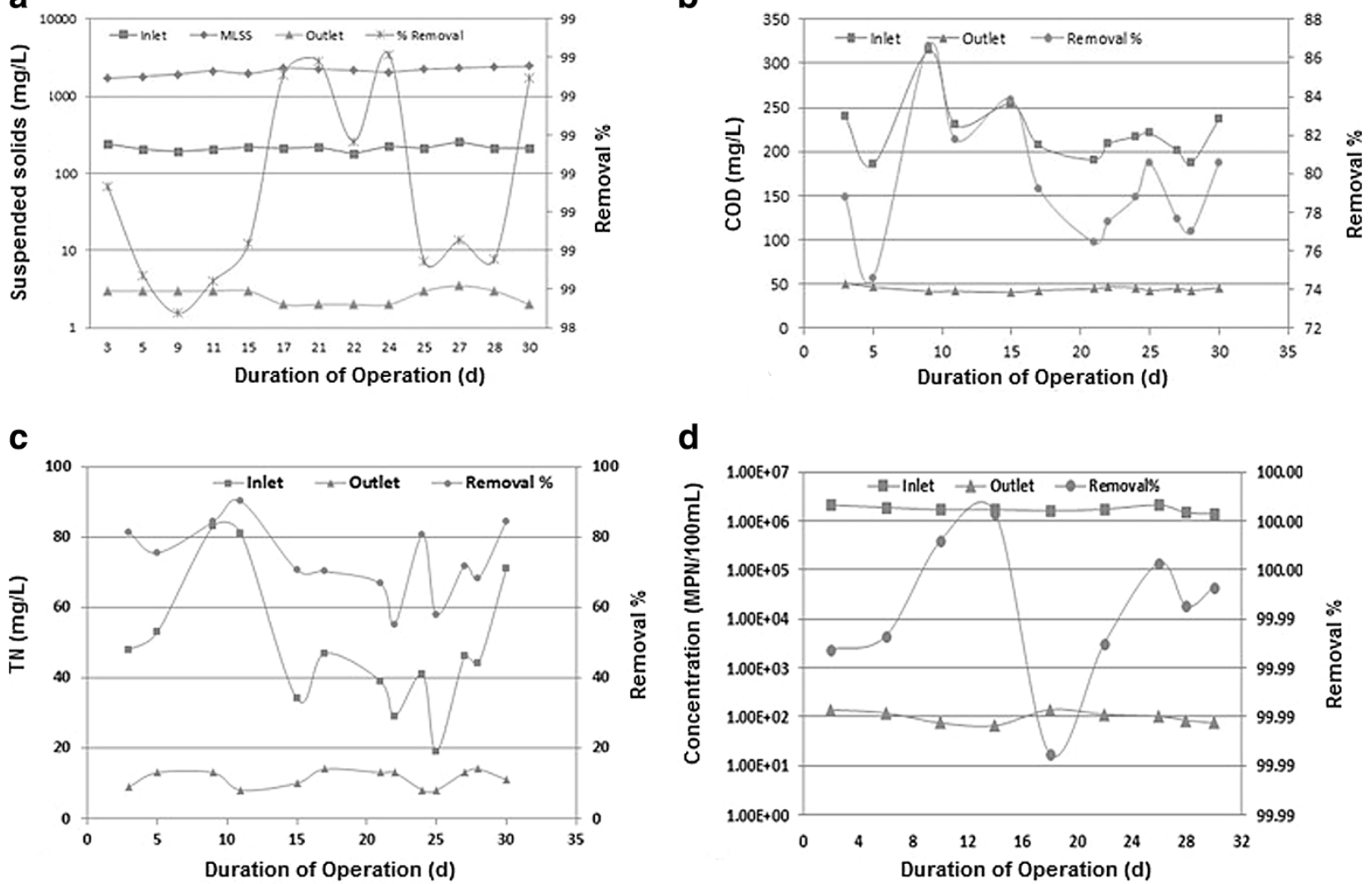

Figure 3 Concentration of SS, COD, TN and TC in inlet and the outlet versus the time of operation and their removal percentage. 


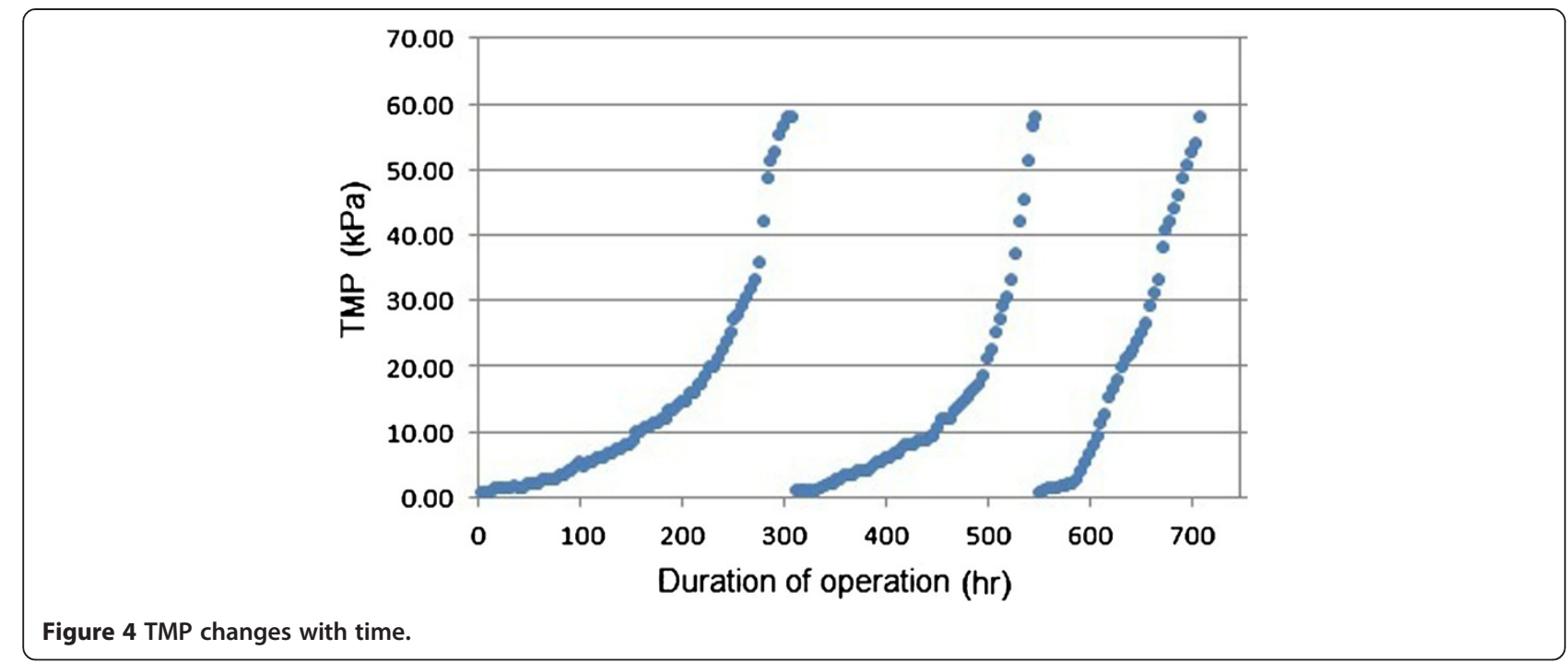

concentration measurements are plotted on a logarithmic scale.

As in Figure 3(a) was shown excellent solids separation achieved by the UF membrane. Removal of SS reached greater than $98 \%$ resulting in the MBR permeate with SS levels below $3 \mathrm{mg} / \mathrm{L}$.

Figure 3(b) shows the removal efficiencies of COD for influent and effluent of MBR reactor. COD was selected as indicator of organic pollution.

It can be seen that the inlet COD varied from $187 \mathrm{mg} / \mathrm{L}$ to $314 \mathrm{mg} / \mathrm{L}$ with the average COD concentration of the influent $222 \mathrm{mg} / \mathrm{L}$ whereas COD concentration in Effluent varied between $41 \mathrm{mg} / \mathrm{L}$ and $51 \mathrm{mg} / \mathrm{L}$ and average elimination rate was higher than $75 \%$. It means MBR system has produced good removal of organic constituents and it was capable of achieving a high removal of COD and therefor organic load could be decreased effectively. Some studies reported more than $90 \%$ of COD removal which is higher than results of this study [22,23]. Lower COD removal in this study may be related to less organic material concentration in the bioreactor. Most of biodegradable organic matters are used by microorganisms during conventional treatment process. Thus, MBR feed stream (WWTP effluent) has lower amount of biodegradable matter.

$\mathrm{TN}$ as one of the parameters representing the content of nutrient matters is widely used in the field of wastewater treatment. Figure 3(c) depicts the TN concentrations in inlet and outlet of the MBR as a function of operation time.

As illustrated in Figure 3(c), during the experimental period, the MBR was able to reduce TN from $51 \pm 32$ $\mathrm{mg} / \mathrm{L}$ in raw wastewater to $11 \pm 3 \mathrm{mg} / \mathrm{L}$ on average. This means that $74 \%$ of the nitrogen was removed. The most likely reason for removal of $\mathrm{TN}$ should be the fact that
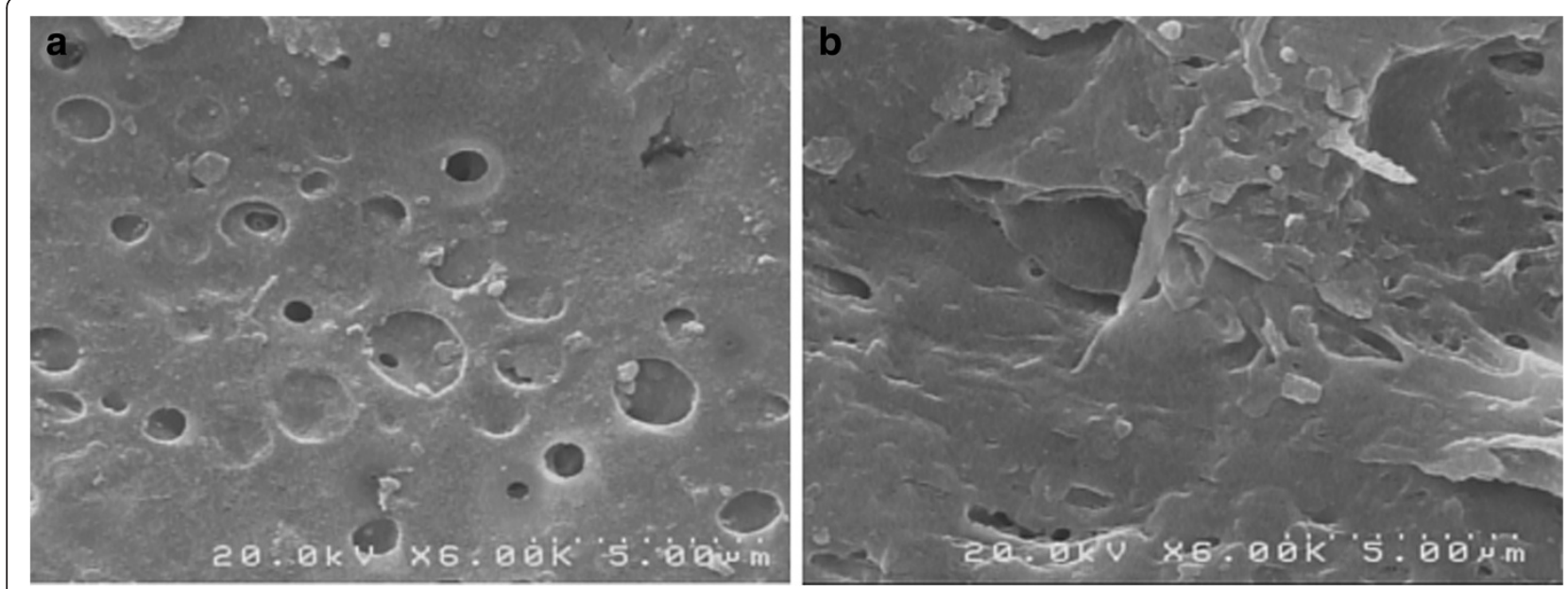

Figure 5 Field emission scanning electron microscopy image of membrane surface: (a) before operation; (b) after operation. 
Table 4 Results of XRF analysis for foulants

\begin{tabular}{ccccccccccccc}
\hline Sample & L.O.I. & $\mathbf{N a}_{\mathbf{2}} \mathbf{O}$ & $\mathbf{M g O}$ & $\mathbf{A l}_{\mathbf{2}} \mathbf{O}_{\mathbf{3}}$ & $\mathbf{S i O}_{\mathbf{2}}$ & $\mathbf{P}_{\mathbf{2}} \mathbf{O}_{\mathbf{5}}$ & $\mathbf{S O}_{\mathbf{3}}$ & $\mathbf{C l}$ & $\mathbf{C a O}$ & $\mathrm{Fe}_{\mathbf{2}} \mathbf{O}_{\mathbf{3}}$ & $\mathbf{Z n}$ & $\mathbf{S r}$ \\
\hline 1 & 42.05 & 0.352 & 0.317 & 0.253 & 0.842 & 0.877 & 0.702 & 0.287 & 53.45 & 0.624 & 0.021 & 0.225 \\
2 & 41.599 & 0.393 & 0.325 & 0.221 & 0.821 & 0.856 & 0.603 & 0.231 & 54.15 & 0.431 & 0.076 & 0.294 \\
3 & 46.251 & 0.392 & 0.294 & 0.18 & 0.851 & 0.811 & 0.522 & 0.229 & 49.066 & 1.000 & 0.065 & 0.339 \\
Ave. (\%) & 43.3 & 0.379 & 0.312 & 0.218 & 0.838 & 0.848 & 0.609 & 0.249 & 52.222 & 0.685 & 0.054 & 0.286 \\
\hline
\end{tabular}

nitrogen was removed mainly through biodegradation by microorganisms and then separation with membrane. Similar results were reported in some previous studies [24-26].

The results of total coliform analyses done on the feed wastewater and MBR permeate are shown in Figure 3 (d). As results show total coliform values in the MBR effluent samples ranged from 75 to $140 \mathrm{MPN} / 100 \mathrm{~mL}$, giving an overall log removal of $>4 \log$ for the total coliforms. As Figure 3(d) shows there is a trend of decreased permeate coliform with increasing time of operation. This would be expected because as the membranes become clogged the pore size is decreased which results in removal of microorganisms and other particles which could normally pass through the membrane. These data show high performance of MBRs for microorganism reduction.

\section{TMP trends of the MBR and membrane fouling}

Membrane fouling behavior could be reflected by the developing rate of transmembrane pressure at the constant flux. As mentioned earlier this constant flux by using a prestaltic pump was set at membrane. The TMP of membrane in this study is the average driving pressure required filtering wastewater through the upper and lower membrane at the given flow rate. In the other hand the TMP is described as below:

$\mathrm{TMP}=\left(\mathrm{P}_{\text {suction }}-\mathrm{P}_{\text {permeate }}\right)(2)$

Where:

$\mathrm{P}_{\text {suction }}=$ Pressure measured on the suction side of the membrane

$\mathrm{P}_{\text {permeate }}=$ Pressure measured on the permeate side of the membrane

In the experiments, the UF membrane flux was set at the constant value of $83 \mathrm{~L} / \mathrm{m}^{2} / \mathrm{h}$ and the change of TMP with time in the MBR was monitored. Figure 4 displayed the trends of flux and TMP versus the date.

It is obvious that TMP increased and went up slowly in exponential manner due to the fouling of the UF membrane. TMP reached $58 \mathrm{kPa}$ on the 13 th day of operation which was the fastest fouled MBR. In this stage particle, colloidal, biological and organic matters rapidly accumulated onto the membrane, and formed a cake which was probably compressible, leading to a rapid increase in the TMP. Some of these foulants are easily removed through physical wash by water, thus called reversible fouling. There is another fouling that is not readily removable from the membrane surface and requires use of chemical cleaning. As was mentioned before, for remove fouling in this study membrane was

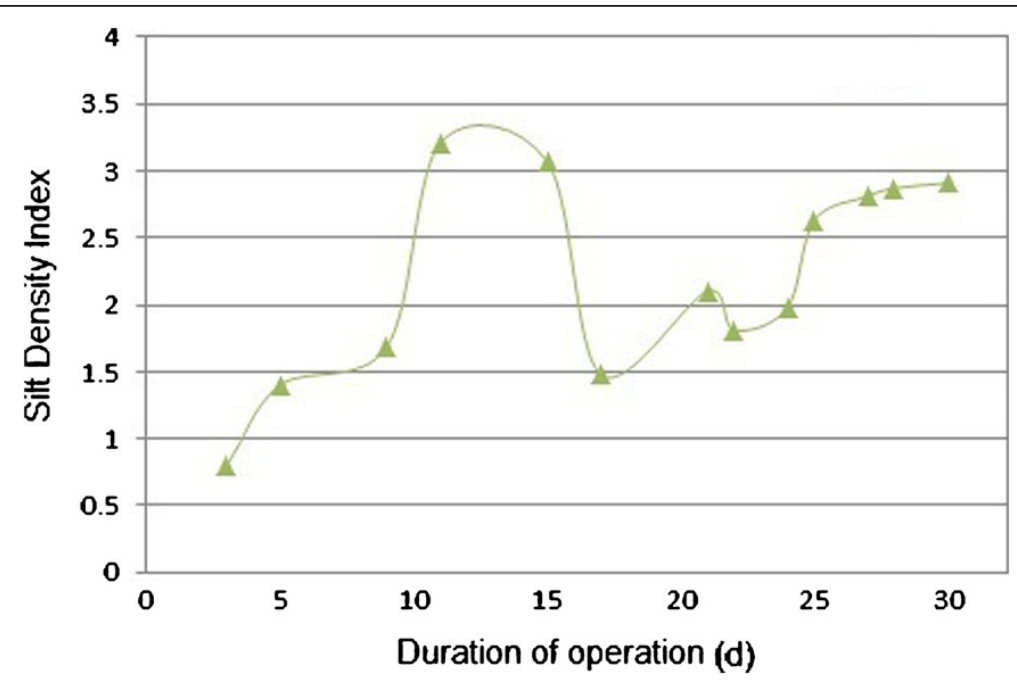

Figure 6 SDI trend of MBR permeate. 
soaked in a $250 \mathrm{mg} / \mathrm{L} \mathrm{NaOCl}$ solution and afterwards with $4000 \mathrm{mg} / \mathrm{L}$ citric acid solution for at least 4 hours. Then membrane was cleaned with tap water. However, it still remains a bit clogging of the membrane pores that are not washed away and caused pore blocking. During operation of MBR and several cleaning of membrane, pore blocking increases. Thus, as was shown in Figure 4, the time interval between the membrane washing is reduced during operation and cleaning of membrane repeats in a shorter duration.

After operation, a stable bio-solids layer was formed inside membrane pores. FESEM observations of the used membrane in the reactor and a clean one were conducted at the end of the investigation to give a visual perspective of the surfaces, as shown in Figure 5.

From Figure 5, it could be seen that in comparison with the flat surface of the clean membrane, an irregular and rough gel layer was extensively distributed on the surface of the membrane in the reactor. The gel layer was found to be mainly consisted of abiotic matter which appeared to be dense and nonporous.

Results of XRF analysis of major components, expressed as percentages of the corresponding oxides, are presented in Table 4. In all samples average of components are: $\mathrm{Na}_{2} \mathrm{O}$ (0.379 \%), $\mathrm{MgO}$ (0.312 \%), $\mathrm{Al}_{2} \mathrm{O}_{3}$ (0.218\%), $\mathrm{SiO}_{2}$ (0.838\%), $\mathrm{P}_{2} \mathrm{O}_{5}(0.848 \%), \mathrm{SO}_{3}$ (0.609\%), $\mathrm{Cl}$ (0.249\%), $\mathrm{CaO}$ (52.222\%), $\mathrm{Fe}_{2} \mathrm{O}_{3}$ (0.685\%), $\mathrm{Zn}(0.054 \%)$ and $\mathrm{Sr}(0.286 \%)$. Other oxides are less abundant.

As it is obvious in Table 4, organic matters and calcium oxides constitute the main components of membrane fouling and contribution of other components such as heavy metals is negligible.

\section{SDI}

As mentioned before, if $\mathrm{RO}$ process feed directly with filtrate wastewater without any pre-treatment it will show a significant increase in process pressure. For evaluation of RO feed water quality, silt density index (SDI) measurements were taken on the MBR permeate water. Figure 6 shows the SDI trend of module permeates. The permeate SDI was below 3 for most of the time, although there was a slight increase and fluctuation during the testing periods. Measured values varied from 1.21 to 3.23 , with the tendency to increase with increasing duration of operation.

In some cases the permeate SDI of the module was more than 3. High levels of organic compounds and associated biofouling, micro-air bubbles and colloidal substances are the three most likely reasons for the unexpected increase in SDI as was mentioned in previous studies $[27,28]$. In general SDI values of less than 3 leading to little fouling by the subsequent RO membranes. Therefore results demonstrate that MBR able to produce high quality effluent so that it would be suitable for use by an RO system.

\section{Conclusions}

In this study the possibility and applicability of MBR to reclaim effluent of an industrial wastewater treatment plant was investigated and the MBR pilot was evaluated in terms of effluent quality. In general, it can be concluded that MBR can produce high permeate quality and is capable to be a very efficient method for RO pretreatment. Product permeate from MBR with average SDI less than 3 indicate that if MBR use as RO pretreatment, it can be anticipated that the rate of RO membrane fouling will reduce and the life of $\mathrm{RO}$ membrane modules will extend.

Through FESEM examinations, a gel layer was observed to be formed on the membrane surface in the MBR during the operation. Analysis of XRF results shows that organic matters and calcium oxides are the main components of membrane fouling.

Also effluent water from the MBR has a high quality according to SS, COD, TN and TC removal during operation. These results are promising and all indications show that this method is feasible for RO pretreatment and water reuse of industrial application.

\section{Competing interests}

The authors declare that they have no competing interests.

\section{Authors' contribution}

$\mathrm{MH}$ has designed and carried out the experiments, analyzed data and wrote the manuscript. AT has conceived the strategies, developed the concept, supervised the study and finalized the manuscript. GNB and NM have guide and advice in the experiments design, suggestion of analysis and manuscript preparation. All authors read and approved the final manuscript.

\section{Acknowledgments}

Experiments in this research were supported by the Qom Water and Wastewater Company and Shokouhieh Industrial Town Director. The authors are grateful to the head of these companies for their helps.

Received: 5 April 2013 Accepted: 23 September 2013

Published: 19 December 2013

\section{References}

1. Tam LS, Tang TW, Lau GN, Sharma KR, Chen GH: A pilot study for wastewater reclamation and reuse with MBR/RO and MF/RO systems. Desalination 2007, 202:106-113.

2. Wintgens T, Melin T, Scha fer A, Khan S, Muston M, Bixio D, Thoeye C: The role of membrane processes in municipal wastewater reclamation and reuse. Desalination 2006, 187:271-282.

3. Comerton AM, Andrews RC, Bagley DM: Evaluation of an MBR-RO system to produce high quality reuse water: microbial control, DBP formation and removal. Water Res 2005, 39:3982-3990.

4. Meier J, Melin T: Wastewater reclamation by PAC/NF process. Desalination 2005, 178:27-40.

5. Radjenovića J, Petrovića M, Venturac F, Barcelóa D: Rejection of pharmaceuticals in nanofiltration and reverse osmosis membrane drinking water treatment. Water Res 2008, 42:3601-3610.

6. Salahi A, Mohammadi T, Rekabdar F, Mahdavi H: Reverse osmosis of refinery Oily wastewater effluents. Iran J Environ Health Sci \& Eng 2010, 7(5):413-422.

7. Gholami M, Mirzaei R, Kalantary R, Sabzali A, Gatei F: Performance evaluation of reverse osmosis technology for selected antibiotics removal from synthetic pharmaceutical wastewater. Iran J Environ Health Sci \& Eng 2012, 9:19. 10 December 2012 
8. Sahar E, David I, Gelman Y, Chikurel H, Aharoni A, Messalem R, Brenner A: the use of RO to remove emerging micropollutants following CAS/UF or MBR treatment of municipal wastewater. Desalination 2011, 273:142-147.

9. Fadhil Abid M, Abdulahad Zablouk M, Muhssen Abid-Alameer A: Experimental study of dye removal from industrial wastewater by membrane technologies of reverse osmosis and nanofiltration. Iran J Environ Health Sci \& Eng 2012, 9:17. 5 December 2012.

10. Alexei G: A simplified RO process design based on understanding of fouling mechanisms. Desalination 1999, 126:227-247.

11. Choia J, Tae-Mun H, Leea S, Hongb S: A systematic approach to determine the fouling index for a RO/NF membrane process. Desalination 2009, 238:117-127.

12. Malamis S, Katsou E, Takopoulos K, Demetriou P, Loizidou M: Assessment of metal removal, biomass activity and $\mathrm{RO}$ concentrate treatment in an MBR-RO system. J Hazard Mater 2012, 209:1-8.

13. Sahar E, David I, Gelman Y, Chikurel H, Aharoni A, Messalem R, Brenner A: The use of RO to remove emerging micropollutants following CAS/UF or MBR treatment of municipal wastewater. Desalination 2011, 237:142-147.

14. Kent F, Farahbakhsh $\mathrm{K}$, Mahendran B, Jaklewicz M, Liss S, Zhou H: Water reclamation using reverse osmosis: analysis of fouling propagation given tertiary membrane filtration and MBR pretreatments. J Membr Sci 2011, 382:328-338.

15. Liu HB, Yang C, Pu WH, Zhang JD: Removal of nitrogen from wastewater for reusing to boiler feed-water by an anaerobic/aerobic/membrane bioreactor. Chem Eng J 2008, 2008(140):122-129.

16. Nelson MI, Balakrishnan EE, Sidhu HS, Chen XD: A fundamental analysis of continuous flow bioreactor models and membrane reactor models to process industrial wastewaters. Chem Eng J 2008, 140:521-528.

17. Dhaouadi $\mathrm{H}$, Marrot $\mathrm{B}$ : Olive mill wastewater treatment in a membrane bioreactor: process feasibility and performances. Chem Eng J 2008, 145:225-231.

18. Lyko S, Al-Halbouni D, Wintgens T, Janot A, Hollender J, Dott W, Melin T: Polymeric compounds in activated sludge supernatant-characterisation and retention mechanisms at full-scale municipal membrane bioreactor. Water Res 2007, 41:3894-3902.

19. Gehlert G, Abdulkadir M, Fuhrmann J, Hapke J: Dynamic modeling of an ultrafiltration module for use in a membrane bioreactor. J Membr Sci 2005, 248:63-71.

20. Ueda T, Hata K, Kikuoka Y, Seino O: Effects of aeration on suction pressure in a submerged membrane bioreactor. Water Res 1997, 31:489-494.

21. APHA, AWWA: Standard method for the examination of water and wastewater. 20th edition. Washington DC: American Public Health Association; 1998.

22. Hoinkis J, Deowana S, Pantenb V, Figolic A, Huangd R, Driolic E: Membrane Bioreactor (MBR) Technology-a Promising Approach for Industrial Water Reuse. Procedia Eng 2012, 33:234-241.

23. Qin J, Wai M, Tao G, Kekre K, Seah H: Membrane bioreactor study for reclamation of mixed sewage mostly from industrial sources. Sep Purif Technol 2007, 53:296-300.

24. Dialynas E, Diamadopoulos E: Integration of a membrane bioreactor coupled with reverse osmosis for advanced treatment of municipal wastewater. Desalination 2009, 238:309-311.

25. Jun Qin J, Kekre KA, Tao G, Oo MH, Wai MN, Cui Lee T, Viswanath B, Seah H: New option of MBR-RO process for production of NEWater from domestic sewage. J Membr Sci 2006, 272:70-77.

26. Hai F, Tessmer K, Nguyen L, Kang J, Price W, Nghiem L: Removal of micropollutants by membrane bioreactor under temperature variation. J Membr Sci 2011, 383:144-151.

27. Sombatsompop K: Membrane fouling studies in suspended and attached growth membrane bioreactor systems. Asian Institute of Technology: Doctoral thesis; 2007

28. Zhang J, Chen L, Zeng H, Yan X, Yang H, Ye C: Pilot testing of outside-in MF and UF modules used for cooling tower blowdown pretreatment of power plants. Desalination 2007, 214:287-298.

doi:10.1186/2052-336X-11-34

Cite this article as: Hosseinzadeh et al.: Evaluation of membrane bioreactor for advanced treatment of industrial wastewater and reverse osmosis pretreatment. Journal of Environmental Health Sciences \& Engineering 2013 11:34.

\section{Submit your next manuscript to BioMed Central and take full advantage of:}

- Convenient online submission

- Thorough peer review

- No space constraints or color figure charges

- Immediate publication on acceptance

- Inclusion in PubMed, CAS, Scopus and Google Scholar

- Research which is freely available for redistribution 